\title{
Gambaran Kecelakaan Kerja dan Penyakit Akibat Kerja Dokter Hewan di Denpasar
}

\author{
Agnes Ayu Biomi \\ Program Studi Kesehatan dan Keselamatan Kerja (K3), Universitas Bali Internasional
}

\begin{abstract}
Abstrak
Latar Belakang: Profesi dokter hewan berisiko terhadap penyakit zoonotic yang secara alami dapat ditularkan dari hewan vertebrata ke manusia atau sebaliknya. Kasus kecelakaan kerja juga terjadi seperti tertusuk jarum suntik, digigit, dicakar dan masih banyak lainnya. Oleh karena itu, penelitian ini dilakukan untuk guna memperoleh gambaran kecelakaan dan penyakit akibat kerja pada dokter hewan.

Metode: Penelitian ini bersifat deskriptif dan populasinya adalah dokter hewan yang bekerja di klinik atau tempat praktek dokter hewan di Denpasar dengan total sampling 42 orang. Data primer dikumpulkan menggunakan kuisioner.

Hasil: Proporsi kecelakaan kerja tertinggi berasal dari kelompok usia antara 25 - 29 tahun yaitu 43\%, lama kerja kurang dari 1 tahun yaitu 48\% dan jenis kelamin perempuan yaitu 67\%. Proporsi kecelakaan kerja berdasarkan klasifikasi seperti jenis kecelakaan paling banyak adalah digigit yaitu 60\%, karena peralatan yaitu 67\%. Sifat luka yang paling banyak terjadi di permukaan yaitu 62\% dan letak luka yang sering terjadi adalah pada tangan yaitu $64 \%$ dan penyakit akibat kerja yang sering dialami dokter hewan adalah scabies.

Kesimpulan: Penyakit akibat kerja pada dokter hewan dipengaruhi oleh usia, lama kerja, dan jenis kelamin. Untuk jenis kecelakaan yang paling sering terjadi diakibatkan oleh kondisi tidak aman dan tindakan tidak aman. Penyakit akibat kerja yang paling banyak adalah penyakit zoonotik. Oleh karena itu pentingnya penerapan kesehatan dan kesehatan kerja di semua bidang pekerjaan termasuk profesi dokter hewan.
\end{abstract}

Kata kunci : kecelakaan kerja, dokter hewan, penyakit akibat kerja.

\section{Accidents and Occupational Diseases of Veterinary Physician in Denpasar}

\begin{abstract}
Background: The veterinarian profession is high risk of zoonotic diseases that transmitted from vertebrates to humans or vice versa. Occupational accidents such as needle sticks, bites, scratches and many others. Therefore, this research was conducted to obtain an overview of occupational accidents and diseases in veterinarians.

Methods: This research is descriptive and the population were veterinarians who work in clinics or veterinary practices in Denpasar with total sampling of 42 persons. Primary data were collected using a questionnaire.

Results: The highest proportion of work accidents came from the age group between 25-29 years were $43 \%$, the length of work was less than 1 year, namely $48 \%$ and the female gender, namely $67 \%$. The proportion of work accidents based on the classification such as types of accidents was mostly bitten about $60 \%$, because of equipment was $67 \%$. The nature of the wounds that mostly occurred on the surface was $62 \%$ and the location of the wounds that often occurred was on the hands about $64 \%$ and the occupational disease that was often experienced by veterinarians was scabies.

Conclusion: Occupational diseases in veterinarians were influenced by age, length of work, and gender. For the types of accidents that occur most often were caused by unsafe conditions and unsafe actions. Most occupational diseases were zoonotic diseases. Therefore the importance of implementing occupational health and health in all fields of work, including the veterinarian profession.
\end{abstract}

Keywords: occupational accidents, veterinarians, occupational diseases.

Korespondensi:Agnes Ayu Biomi

Email: agnesayubiomi@iikmpbali.ac.id 


\section{PENDAHULUAN}

Badan Kesehatan Dunia (WHO) menyatakan sekitar $75 \%$ emerging infectious disease (EID) yang menginfeksi manusia merupakan penyakit zoonotik. ${ }^{1}$ Menurut Lembaga Occupational Information Network, salah satu profesi yang berisiko tinggi terhadap EID yaitu dokter hewan karena berinteraksi langsung dengan hewan dan manusia. Risiko terhadap EID selama dokter hewan bekerja dapat berasal dari peralatan kerja. Dapat dikatakan bahwa profesi dokter hewan memungkinkan terjadinya pemaparan terhadap resiko kecelakaan dan penyakit akibat kerja (PAK). ${ }^{2}$

Dokter hewan berinteraksi dengan hewan yang tingkah laku hewannya tidak dapat diprediksi, bahkan hewan jinak sekalipun sehingga dokter hewan memiliki risiko cidera yang cukup tinggi. Hewan memiliki insting untuk melindungi diri sehingga dokter hewan harus berhati - hati dan menggunakan teknik dalam menangani hewan pasiennya. Kecelakaan kerja sebesar $3 \%$ disebabkan oleh hal - hal yang tidak dapat dihindarkan, seperti bencana alam, $24 \%$ karena lingkungan atau peralatan yang tidak memenuhi syarat dan $73 \%$ karena perilaku yang tidak aman. ${ }^{3}$

Kecelakaan kerja dan masalah kesehatan pada profesi dokter hewan cukup tinggi namun masih belum banyak didokumentasikan, maka penelitian perlu dilakukan untuk memberikan gambaran kecelakaan kerja dan penyakit akibat kerja dokter hewan terutama di Denpasar sehingga diharapkan dari penelitian ini dapat muncul perhatian khusus pada profesi dokter hewan untuk menurunkan risiko kecelakaan dan penyakit akibat kerja.

\section{METODE}

Penelitian ini bersifat deskriptif dan merupakan penelitian pendahuluan untuk mengetahui seberapa besar atau sering kecelakaan terjadi pada dokter hewan melalui gambaran kecelakaan kerja dan penyakit akibat kerja dokter hewan di Denpasar yang dilakukan pada bulan Agustus sampai Oktober 2020. Penelitian dilakukan pada 42 dokter hewan yang bekerja di klinik atau tempat praktek dokter hewan di Denpasar secara total sampling.
Variabel penelitian ini yaitu usia, jenis kelamin, lama bekerja, penyebab kecelakaan, jenis kecelakaan, sifat luka, letak luka dan penyakit akibat kerja. Instrumen yang digunakan yaitu kuesioner dan pengumpulan data melalui wawancara. Data yang diperoleh dianalisis secara deskriptif dan disajikan berdasarkan distribusi frekuensi dan proporsi.

\section{HASIL}

Pada Tabel 1 dapat diketahui bahwa usia dokter hewan yang paling banyak yaitu usia 25 - 29 tahun sejumlah 18 orang $(43 \%)$. Distribusi menurut masa kerja di klinik atau tempat praktek paling banyak mengalami kecelakaan kerja adalah masa kerja kurang dari 1 tahun sebanyak 20 orang (48\%). Dokter hewan yang berjenis kelamin perempuan yang lebih banyak mengalami kecelakaan kerja sejumlah 28 orang (67\%).

Tabel 1 Karakteristik Responden

\begin{tabular}{lll}
\hline Karakteristik & $\begin{array}{l}\text { Jumlah } \\
\text { (orang) }\end{array}$ & $\begin{array}{l}\text { Persentase } \\
\text { (\%) }\end{array}$ \\
\hline Usia (Tahun) & & \\
$25-29$ & 18 & 43 \\
$30-34$ & 13 & 31 \\
$35-39$ & 8 & 19 \\
$40-44$ & 3 & 7 \\
\hline Masa Kerja & & \\
(Tahun) & & \\
$<1$ & 20 & 48 \\
$2-6$ & 12 & 29 \\
$7-10$ & 10 & 23 \\
\hline Jenis Kelamin & & \\
Laki - laki & 14 & 33 \\
Perempuan & 28 & 67 \\
\hline
\end{tabular}

Gambaran kecelakaan kerja
berdasarkan klasifikasi seperti jenis
kecelakaan, penyebab kecelakaan, sifat luka
dan letak luka. Pada Tabel 2 ditunjukkan
bahwa jenis kecelakaan yang paling sering
terjadi adalah digigit (60\%) dan akibat
peralatan $(67 \%)$. Menurut sifat luka yang
paling sering terjadi luka di permukaan
(62\%), sedangkan letak luka yang paling
sering dialami adalah di tangan (64\%).
Penyakit yang paling sering dialami adalah
penyakit skabies $(43 \%)$.

Gambaran kecelakaan kerja berdasarkan klasifikasi seperti jenis kecelakaan, penyebab kecelakaan, sifat luka dan letak luka. Pada Tabel 2 ditunjukkan bahwa jenis kecelakaan yang paling sering tejadi adalah digigit (60\%) dan akibat peralatan $(67 \%)$. Menurut sifat luka yang paling sering terjadi luka di permukaan (62\%), sedangkan letak luka yang paling sering dialami adalah di tangan (64\%). penyakit skabies $(43 \%)$. 
Tabel 2. Gambaran Kecelakaan Kerja dan Penyakit Akibat Kerja

\begin{tabular}{|c|c|c|}
\hline $\begin{array}{l}\text { Gambaran } \\
\text { Kecelakaan Kerja } \\
\text { dan PAK }\end{array}$ & $\begin{array}{l}\text { Jumlah } \\
\text { (orang) }\end{array}$ & $\begin{array}{l}\text { Persentase } \\
(\%)\end{array}$ \\
\hline \multicolumn{3}{|l|}{ Jenis Kecelakaan } \\
\hline Digigit & 25 & 60 \\
\hline Dicakar & 13 & 31 \\
\hline $\begin{array}{l}\text { Tertusuk jarum } \\
\text { suntik }\end{array}$ & 4 & 9 \\
\hline Total & 42 & 100 \\
\hline \multicolumn{3}{|l|}{ Penyebab } \\
\hline Peralatan & 28 & 67 \\
\hline $\begin{array}{l}\text { Bahan - bahan dan } \\
\text { zat }\end{array}$ & 14 & 33 \\
\hline Total & 42 & 100 \\
\hline \multicolumn{3}{|l|}{ Sifat Luka } \\
\hline Luka di permukaan & 26 & 62 \\
\hline Luka - luka lain & 16 & 38 \\
\hline Total & 42 & 100 \\
\hline \multicolumn{3}{|l|}{ Letak Luka } \\
\hline Tangan & 27 & 64 \\
\hline Badan & 15 & 36 \\
\hline Total & 42 & 100 \\
\hline $\begin{array}{l}\text { Penyakit } \\
\text { dialami }\end{array}$ & & \\
\hline Scabies & 18 & 43 \\
\hline Leptospirosis & 16 & 38 \\
\hline Jamur & 6 & 14 \\
\hline Cacingan & 2 & 5 \\
\hline Total & 42 & 100 \\
\hline
\end{tabular}

\section{PEMBAHASAN}

Penelitian ini menemukan bahwa dokter hewan berusia 25 - 29 tahun paling sering mengalami kecelakaan kerja. Penelitian sebelumnya mengenai tes refleks juga menunjukkan bahwa tingkat kecelakaan kerja usia muda tinggi. ${ }^{4} \mathrm{Hal}$ ini disebabkan oleh kecerobohan, kelalaian dan kontrol emosi yang masih labil sehingga mempengaruhi fokus dan konsentrasi yang belum stabil. Lama bekerja kurang dari 1 tahun sering mengalami kecelakaan kerja karena dengan meningkatnya pengalaman dan keterampilan disertai dengan penurunan angka kecelakaan. ${ }^{5} \quad$ Kewaspadaan terhadap kecelakaan bertambah baik sesuai masa kerja dan lama kerja di tempat kerja yang bersangkutan. Dengan demikian kecelakaan kerja terjadi karena tenaga kerja baru belum mengetahui secara mendalam tentang pekerjaan dan keselamatannya sehingga keselamatan belum mendapat cukup perhatian. Kecelakaan kerja dan penyakit akibat kerja cenderung akan menjadi perhatian ketika kecelakaan itu sudah terjadi. ${ }^{6}$ Dokter hewan perempuan lebih banyak jumlahnya dalam penelitian ini. Perbedaan pola pikir dan cara kerja antara laki - laki dan perempuan berpengaruh juga pada prilaku keselamatan kerja. ${ }^{7}$ Perempuan cenderung berhati - hati dan lebih lambat dalam menangani hewan karena masih takut dan cemas. Sedangkan pada laki - laki lebih teknis dan logis sehingga penanganan pada hewan, laki - laki lebih berani dan cepat dalam mengambil keputusan. ${ }^{8}$

Berdasarkan hasil penelitian, jenis kecelakaan kerja yang sering terjadi yang dialami dokter hewan adalah digigit hewan pasiennya seperti anjing. Anjing menggigit sebagai upaya perlindungan dirinya, terutama anjing yang pertama kali atau baru bertemu dengan dokter hewan. Gigitannya tidak beresiko apabila anjing tersebut sudah divaksinasi namun jika belum dapat menyebabkan rabies atau infeksi tetanus. ${ }^{9}$ Diperlukan perawatan medis lebih lanjut jika gigitan berasal dari anjing penderita atau rabies. ${ }^{10}$ Oleh karena itu, dokter hewan juga harus menyiapkan alat pelindung diri berupa sarung pelindung tangan untuk menghindari gigitan anjing langsung ke permukaan kulit. Penyebab kecelakaan yang sering terjadi disebabkan oleh peralatan salah satunya jarum suntik. ${ }^{11}$ Hewan yang tidak terbiasa ke dokter hewan, reaksi yang terjadi salah satunya adalah berusaha menghindar dan pergerakannya tidak terduga sehingga ketika akan disuntik, hewan melakukan perlawanan dan menyebabkan dokter hewan tertusuk jarum suntik. Begitu juga ketika hewan yang sudah sering ke dokter hewan pun akan mencoba menghindar dan melakukan pergerakan yang tidak terduga karena merasa trauma dan lain - lain. Maka ketika hewan hendak disuntik sebaiknya dokter hewan dibantu pemilik atau asisten dokter hewan untuk memegang hewan supaya tidak bergerak atau memberontak atau diberikan moncong penutup mulut hewan apabila hewan tersebut menggigit dan selalu menyiapkan alat pelindung diri. ${ }^{12}$

Sifat luka yang paling sering terjadi di permukaan dan tangan akibat digigit atau 
tertusuk jarum. Zoonosis adalah infeksi yang ditularkan di antara hewan vertebrata dan manusia atau sebaliknya. Dokter hewan sering melakukan interaksi dengan hewan yang memiliki berbagai riwayat penyakit dan mempunyai resiko menularkan penyakitnya ke manusia sehingga resiko kesehatan dokter hewan cukup tinggi. ${ }^{13}$ Penyakit zoonosis yang paling banyak dialami dokter hewan adalah scabies. Scabies atau lebih dikenal dengan kudis penularannya dapat terjadi melalui kontak kulit yang menyebabkan gatal. ${ }^{14}$ Oleh karena itu sangat penting juga bagi dokter hewan selalu menjaga higienitas personal, setelah treatment atau melakukan kontak dengan hewan tidak lupa mencuci tangan dengan sabun. ${ }^{15}$

\section{KESIMPULAN}

Penelitian ini menemukan bahwa penyakit akibat kerja pada dokter hewan dipengaruhi oleh usia, lama kerja, dan jenis kelamin. Untuk jenis kecelakaan yang paling sering terjadi diakibatkan oleh kondisi tidak aman dan tindakan tidak aman. Penyakit akibat kerja yang paling banyak adalah penyakit zoonotik. Oleh karena itu, penting dilakukan pelatihan tentang kesehatan dan keselamatan kerja terhadap dokter hewan agar dapat mengurangi angka kecelakaan kerja dan penyakit akibat kerja serta meningkatkan pengetahuan dokter hewan mengenai pengendalian resiko dan bahaya pekerjaannya. Pemerintah juga perlu mensosialisasikan hal - hal yang berhubungan dengan kesehatan dan keselamatan kerja. Menyediakan fasilitas alat pelindung diri (APD) sesuai dengan standar yang berlaku serta SOP penggunaan APD. Faktor - faktor yang mempengaruhi kecelakaan kerja dan penyakit akibat kerja pada dokter hewan yang lebih luas yang belum diteliti, diharapkan dapat diteruskan pada penelitian selanjutnya.

\section{DAFTAR PUSTAKA}

1. Dowd, K. T. Perception of the Risk of Zoonosis and The Practice of Australian Veterinary Infection Control : a call for change in work culture. USA: Veterinary Medicine;2013.
2. Krauss, H. W. Zoonoses Infectious Diseases Transmissibe from Animal to Human 3rd. ASM Press;2003.

3. Health, D. O. Guidelines for Hazard Identification, Risk Assesment and Risk Control. Malaysia;2008.

4. Suma'mur. Keselamatan Kerja dan Pencegahan Kecelakaan. Jakarta: Haji Masagung;1989.

5. Tarwaka. Manajemen dan Implementasi K3 di Tempat Kerja. Surakarta: Harapan Press;2008.

6. Sulaksmono, M. Manajemen Keselamatan Kerja. Surabaya: Pustaka;1997.

7. Budiana. Anjing. Jakarta: Penebar Swadaya;2009.

8. McCurnin, D. Clinical Textbook for Veterinary Technicans. London: Saunders Company; 1985.

9. Rogers, B. Health Hazard in Animal Care. Occupational and Environmental Medicine. London: BMJ Journal;2018.

10. Linda, T. Panduan Pencegahan Infeksi Untuk Fasilitas Pelayanan Kesehatan dengan Sumber Daya Terbatas. Jakarta: Yayasan Bina Pustaka;2014.

11. B, Silalahi. Manajemen Keselamatan dan Kesehatan Kerja. Jakarta: Gramedia;2010.

12. Heni, Y. Improving Our Safety Culture. Jakarta: Gramedia;2000.

13. Irzal. Dasar - dasar Kesehatan dan Keselamatan Kerja. Jakarta: Kencana;2016.

14. Radjagukguk, J. Gambaran Kecelakaan Kerja Pada Pekerja Pabrik Kelapa Sawit PTPN IV Kebun Bah Jambi Tahun 2006-2008. Jambi;2009.

15. Rejeki, S. Hygiene dan Kesehatan dan Keselamatan Kerja (K3). Bandung: Rekayasa Sains;2015. 